\title{
Does the Attention Deficit Hyperactivity Disorder interfere with bariatric surgery results?
}

\section{O Transtorno de Déficit de Atenção e Hiperatividade interfere nos resultados da cirurgia bariátrica?}

Doglas Gobbi Marchesi, TCBC-ES'; Jovana Gobbi Marchesi Ciriaco²; Gustavo Peixoto Soares Miguel, TCBC-ES'; Gustavo Adolfo Pavan Batista, ACBC-ES'; Camila Pereira Cabral, ACBC-ES'1; larissa Carvalho Fraga¹.

\section{A B S T R A C T}

\begin{abstract}
Objective: to analyze possible negative effects of Attention Deficit Hyperactivity Disorder (ADHD) on the success of bariatric surgery. Methods: we evaluated forty patients undergoing bariatric surgery and with regular post-operative follow-up of at least one year. To all, we applied the questionnaire advocated in the fourth edition of the Diagnostic and Statistical Manual (DSM-IV) of the American Psychiatric Association for $A D H D$, as well as analyzed their postoperative data. Results: fifteen (38\%) patients presented a positive questionnaire for $A D H D$. Patients with ADHD presented higher BMI than patients without the disorder (45.8 vs. $40.9 \mathrm{~kg} / \mathrm{m}^{2}, p=0.017$ ), and the difference remained in all postoperative stages. There was no statistically significant difference in surgery success $(33.3 \% \times 66.7 \%, p=0.505)$ or in $B M I$ reduction $(30.71 \% \times 31.88 \%, p=0.671)$ one year after the procedure. Conclusion: ADHD patients have a higher BMI. However, the presence of $A D H D$ does not influence the success of bariatric surgery and the reduction of BMI.
\end{abstract}

Keywords: Bariatric surgery. Obesity. Attention Deficit Disorder with Hyperactivity.

\section{INTRODUCTION}

$\mathrm{O}$ besity is a chronic disease that affects an increasing number of individuals worldwide ${ }^{1,2}$. There are estimates of overweight prevalence of $50.6 \%{ }^{3}$. It is associated with a significant increase in morbidity and mortality and raises the incidence of several diseases, among them hypertension, diabetes mellitus, metabolic syndrome ${ }^{4-7}$.

Bariatric surgery is a definitive treatment for morbid obesity and presents good long-term results, with loss of up to $70 \%$ excess weight ${ }^{8}$. The most commonly performed technique in Brazil and the world is the Roux-en-Y Gastric Bypass (RYGB).

Despite the great efficiency of bariatric surgery, about 10 to $20 \%$ of patients submitted to it regain weight after the procedure ${ }^{9,10}$. Both the weight regain and the procedure failure are due to multiple factors. Psychiatric disorders such as anxiety, depression and attention-deficit / hyperactivity disorder (ADHD) are listed among them ${ }^{9,10}$.
ADHD is a neurological disorder of genetic causes $^{11,12}$, present in about $5 \%$ of the adult population ${ }^{13,14}$. Symptoms revolve around the triad of inattention, restlessness, and impulsivity of varying degrees $^{15}$. The etiology of ADHD is still unknown, but recent studies suggest alterations in the reward mechanism, also related to eating disorders and obesity $^{16}$. There is evidence of increased ADHD incidence among obese and of greater difficulty in adherence to treatments and weight control ${ }^{17}$. However, few studies have evaluated the prevalence of ADHD in candidates for bariatric surgery and no study has evaluated its possible effects on the success of this procedure.

The purpose of this study was to evaluate the effect of the presence of ADHD on the results of bariatric surgery.

\section{METHODS}

We conducted a retrospective, observational study under the approval of the Ethics in Research

1 - Federal University of Espírito Santo, Department of Surgical Clinics, Vitória, Espírito Santo State, Brazil. 2 - Federal University of Espírito Santo, Department of Internal Medicine, Vitória Espírito Santo State, Brazil. 
Committee (CEP) of the Federal University of Espírito Santo (UFES) (CAAE: 05524512.3.0000.5060). We analyzed the specific charts of the bariatric surgery program of patients undergoing bariatric surgery from November 2011 to May 2013, according to the inclusion and exclusion criteria mentioned below.

After the selection of the volunteers, we obtained a list of 122 patients, who were invited to attend the Bariatric Surgery Outpatient Clinic of the Cassiano Antônio de Moraes University Hospital (HUCAM), where they signed the Informed Consent Form.

The inclusion criteria were patients submitted to the RYGB, respecting the indications of bariatric surgery according to the guideline of the National Institute of Health $(\mathrm{NIH})^{6}$, postoperative time

Figure 1. Algorithm of patient selection.

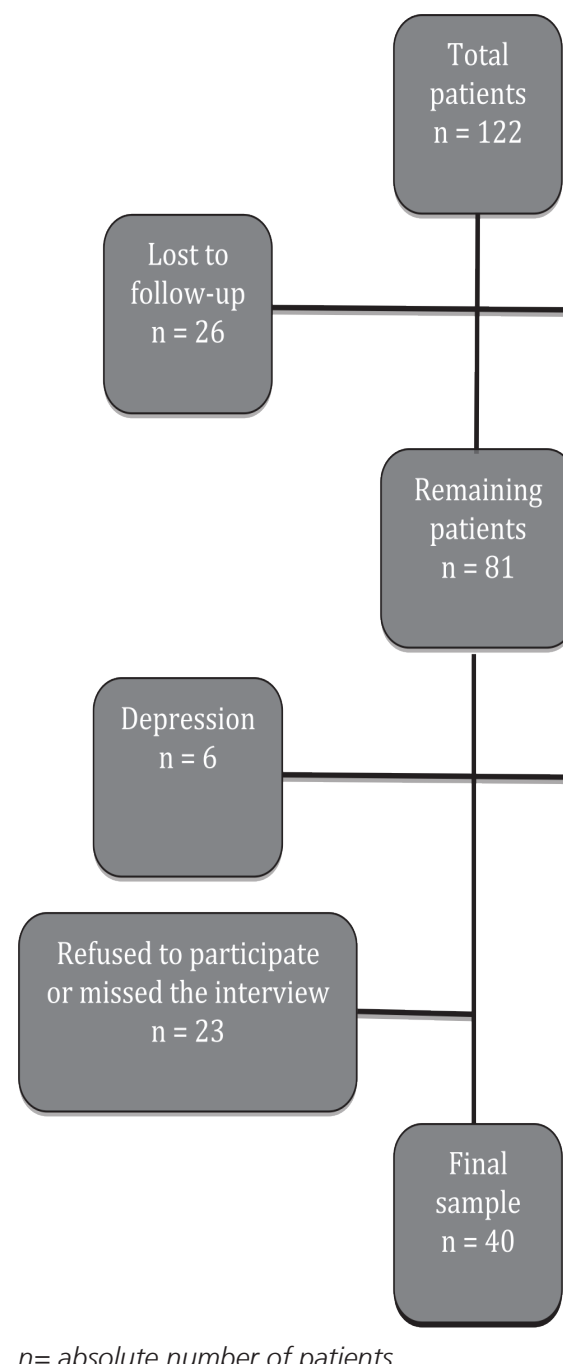

Incorrect or

lost data

$\mathrm{n}=15$

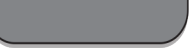

Age

Weight

$\mathrm{BMI}$

Psychoactive

drugs

$\mathrm{n}=12$

Ethnicity

Exclusion criteria were diagnosis of neurological and/or psychiatric diseases and use of psychoactive medications, to avoid confusion bias due to symptoms' masking.

After this initial screening, we included 40 patients for data evaluation, according to the algorithm shown in figure 1.

After data collection, we performed a descriptive analysis with mean, standard deviation, median, absolute frequency and percentage, as well as maximum and minimum values, and drew up a profile of the cohort, recording data such as schooling, marital status, profession, age, ethnicity and comorbidities, seenin table 1 .

Table 1. Characterization of the sample.

\begin{tabular}{|c|c|}
\hline Variables & Results \\
\hline Gender & $\begin{aligned} \text { Male } & =8 \% \\
\text { Female } & =93 \%\end{aligned}$ \\
\hline Marital Status & $\begin{array}{c}\text { Married }=68 \% \\
\text { Not married }=32 \%\end{array}$ \\
\hline Profession & $\begin{array}{l}\text { With profession }=70 \% \\
\text { No occupation }=30 \%\end{array}$ \\
\hline Age & $\begin{array}{c}\text { Average } \pm S D=48.3 \pm 10.2 \\
\text { Median }=50\end{array}$ \\
\hline Weight & $\begin{array}{c}\text { Average } \pm \text { SD }=110.9 \pm 19.2 \\
\text { Median }=109.5\end{array}$ \\
\hline $\mathrm{BMl}$ & $\begin{aligned} \text { Average } \pm S D & =43.9 \pm 6.1 \\
\text { Median } & =42.6\end{aligned}$ \\
\hline Ethnicity & $\begin{array}{c}\text { White }=25 \% \\
\text { Brown }=43 \% \\
\text { Black }=33 \%\end{array}$ \\
\hline Schooling & $\begin{array}{c}\text { Incomplete Junior high= }=26 \% \\
\text { Complete Junior high= } 11 \% \\
\text { Complete High school }=34 \% \\
\text { Incomplete High school= } 11 \% \\
\text { Incomplete College = 5\% } \\
\text { Complete College= } 13 \%\end{array}$ \\
\hline ADHD & $\begin{array}{l}\text { Positive }=38 \% \\
\text { Negative }=62 \%\end{array}$ \\
\hline Type of ADHD & $\begin{array}{c}\text { Pure attention deficit }=27 \% \\
\text { Pure hyperactivity }=27 \% \\
\text { Mixed }=56 \%\end{array}$ \\
\hline
\end{tabular}


Table 2. Relationship between number of Comorbidities and ADHD.

\begin{tabular}{cccccc}
\hline & \multicolumn{5}{c}{ Number of Comorbidities } \\
ADHD & $\mathrm{n}$ & Median & Average & Standard deviation & p-value* $^{*}$ \\
\hline Yes & 15 & 4.00 & 3.13 & 1.25 & 0.075 \\
No & 25 & 2.00 & 2.32 & 2.32 & \\
\hline
\end{tabular}

* Mann-Whitney Test.

We followed the patients at the institution's bariatric surgery outpatient clinic with programmed returns for three months, six months and one year. We evaluated variables such as weight, body mass index (BMI), percentage of $\mathrm{BMI}$ loss, and success of bariatric surgery (defined as loss of $50 \%$ or more of excess weight, considering a BMI of $\left.25^{8,18}\right)$. In addition, researchers previously trained by a neurologist applied the Adult-Self Report Scale (ASRS) structured questionnaire ${ }^{11}$, for the diagnosis of ADHD. The questionnaire has 18 questions, the answers of which are divided into five groups (never, rarely, sometimes, often, very often), and grouped in part $A$ (nineattention deficit questions) and part $B$ (nine hyperactivity questions). For ADHD diagnosis, we used the criteria of the fourth American Diagnostic and Statistical Manual of Mental Disorders (DSMIV) ${ }^{19}$ of the American Psychiatry Society, and deemed present when six or more responses were positive in part A or part B, or both, not considering the sum of the positive answers in the two parts. We divided the patients into two groups: with ADHD and without ADHD.

In the comparative analysis, for categorical variables, the statistical technique used was the chi-square test. For metric variables between two groups, we used the t-test for mean (parametric) and the Mann-Whitney test (non-parametric) for the comparisons. Statistical significance was set at $p<0.05$.

\section{RESULTS}

Of the 40 patients evaluated in the one-year period, 24 (60\%) were successful. The ADHD group showed a higher average of comorbidities, but there was no statistically significant difference (Table 2).
We observed a statistically significant difference in BMI at all times of follow-up. (Table 3).

When comparing the percentage of $\mathrm{BMI}$ loss, ADHD individuals had a statistically significant difference in six months; however, this difference did not persist after 12 months (Figure 2).

Both in the absolute weight loss assessment and in the comparative analysis of surgery success, there was no statistically significant difference between the groups with and without ADHD (Table 4).

\section{DISCUSSION}

The relationship between ADHD and obesity became clear in recent years, both because of similar etiopathogeneses ${ }^{16}$ and because of the difficulty in adhering to treatments and weight control17. Concomitantly, despite the efficiency of bariatric surgery, a not insignificant portion of the patients, up to $20 \%$, presented weight regain and the associated relapse of some comorbidities ${ }^{9,10}$. Faced with this situation, review studies performed to evaluate psychosocial predictors of failure in bariatric surgery have shown that the vast majority of studies are conflicting and inconclusive 20,21 . This result is

Figure 2. Percentage reduction of BMI.

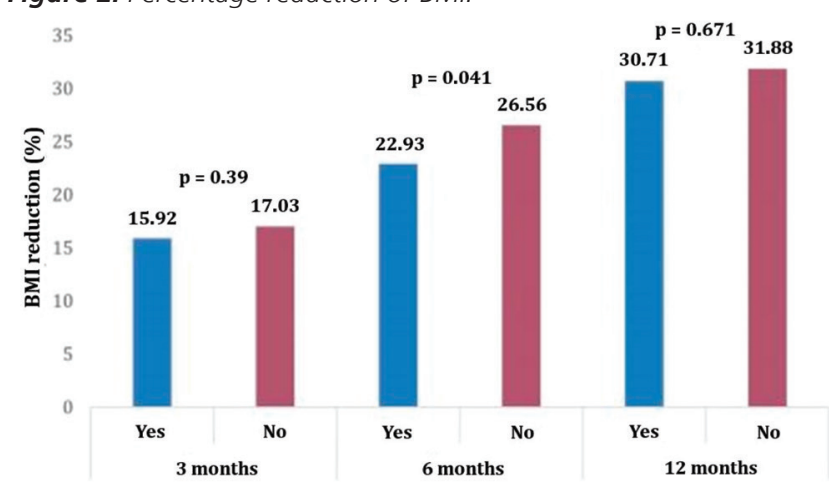

Yes= with $A D H D ; N o=$ no $A D H D$ 
Table 3. BMlaccording to ADHD.

\begin{tabular}{|c|c|c|c|c|c|c|}
\hline Variables & $A D H D$ & $\mathrm{n}$ & Median & Average & Standard deviation & p-value* \\
\hline \multirow{2}{*}{ BMI (pre-op) } & Yes & 15 & 45.80 & 47.09 & 6.75 & \multirow{2}{*}{0.017} \\
\hline & No & 25 & 40.90 & 42.03 & 4.98 & \\
\hline \multirow{2}{*}{ BMI (3 months) } & Yes & 13 & 37.80 & 40.15 & 6.01 & \multirow{2}{*}{0.007} \\
\hline & No & 24 & 32.60 & 34.82 & 4.61 & \\
\hline \multirow{2}{*}{ BMI (6 months) } & Yes & 11 & 34.50 & 36.42 & 5.51 & \multirow{2}{*}{0.003} \\
\hline & No & 23 & 29.50 & 30.98 & 4.07 & \\
\hline \multirow{2}{*}{ BMI (12 months) } & Yes & 15 & 31.00 & 32.49 & 6.16 & \multirow{2}{*}{0.022} \\
\hline & No & 25 & 27.10 & 28.52 & 3.85 & \\
\hline
\end{tabular}

* Mann-Whitney Test.

due in part to the fact that manybariatric surgery teamsautomaticallyconsider patients diagnosed with psychiatric disorders as ineligible for the procedure ${ }^{20}$.

The prevalence of $38 \%$ of ADHD found in our sample was in line with the studies that evaluated obese patients in general $17,22,23$ and with a value far above that found in patients in bariatric surgery programming 24,25 . Studies evaluating the obese population in general found a prevalence of ADHD between 27.4 and $32.2 \%,{ }^{17,22,23}$ but one of the studies identified a higher incidence in individuals with $\mathrm{BMI}=40 \mathrm{~kg} / \mathrm{m}^{2} 22$. Two of these studies used as a diagnostic method a semi-structured interview and psychological follow-up ${ }^{17,22}$. Pagoto et al. ${ }^{23}$ used the same ASRS scale that we used in our study, but considered as positive the patients that met four criteria only. Thus, these studies opted for greater sensitivity in diagnosis.

On the other hand, studies in groups of patients in preoperative bariatric surgery showed prevalence between 10.2 and $12.1 \%{ }^{24,25}$. However, Gruss et al. ${ }^{24}$ considered positive only those patients who fulfilled criteria in two scales. When evaluating only the ASRS use, they found a prevalence of $29.3 \%$, which is the closest to our result. We also note that these two studies used the ASRS scale with the patient reading and completing it alone, while in our study the researchers/interviewers conducted the questionnaire, as previously trained. We consider this adaptation necessary since we work with a portion of the population of low socioeconomic level, which would compromise the understanding of the questionnaire and its due fulfillment. In addition, we increased the accuracy of the diagnosis and avoided false-negative results.

Regarding comorbidities, we observing no difference between the patients with ADHD and the group without the disorder. We found no articles in the literature comparing these variables. We believe that the obesity degree directly influences the number of comorbidities ${ }^{6}$, without direct influence of ADHD.

We observed that the BMI of patients with ADHD were higher than of those without the diagnosis. An American epidemiological study of 2013 with 34,653 people directly interviewed by psychiatrists confirmed that there was a significant difference in both weight and $\mathrm{BMI}$ in $\mathrm{ADHD}$ individuals ${ }^{26}$, which corroborates our results.

Our success rate with surgery was $60 \%$ after one year. However, some factors may have negatively influenced this result. The maximum weight loss can occur up to the second postoperative year ${ }^{27}$. Our serieshad a large proportion of blacks, who display less weight loss in bariatric surgery ${ }^{28}$. Finally, weight loss after bariatric surgery is usually lower in superobese patients and in diabetics ${ }^{29,30}$. Thus, one expects that in a sample with a high percentage of diabetics and 
Table 4. Weight loss according to presence of ADHD.

BMI percentage loss (\%)

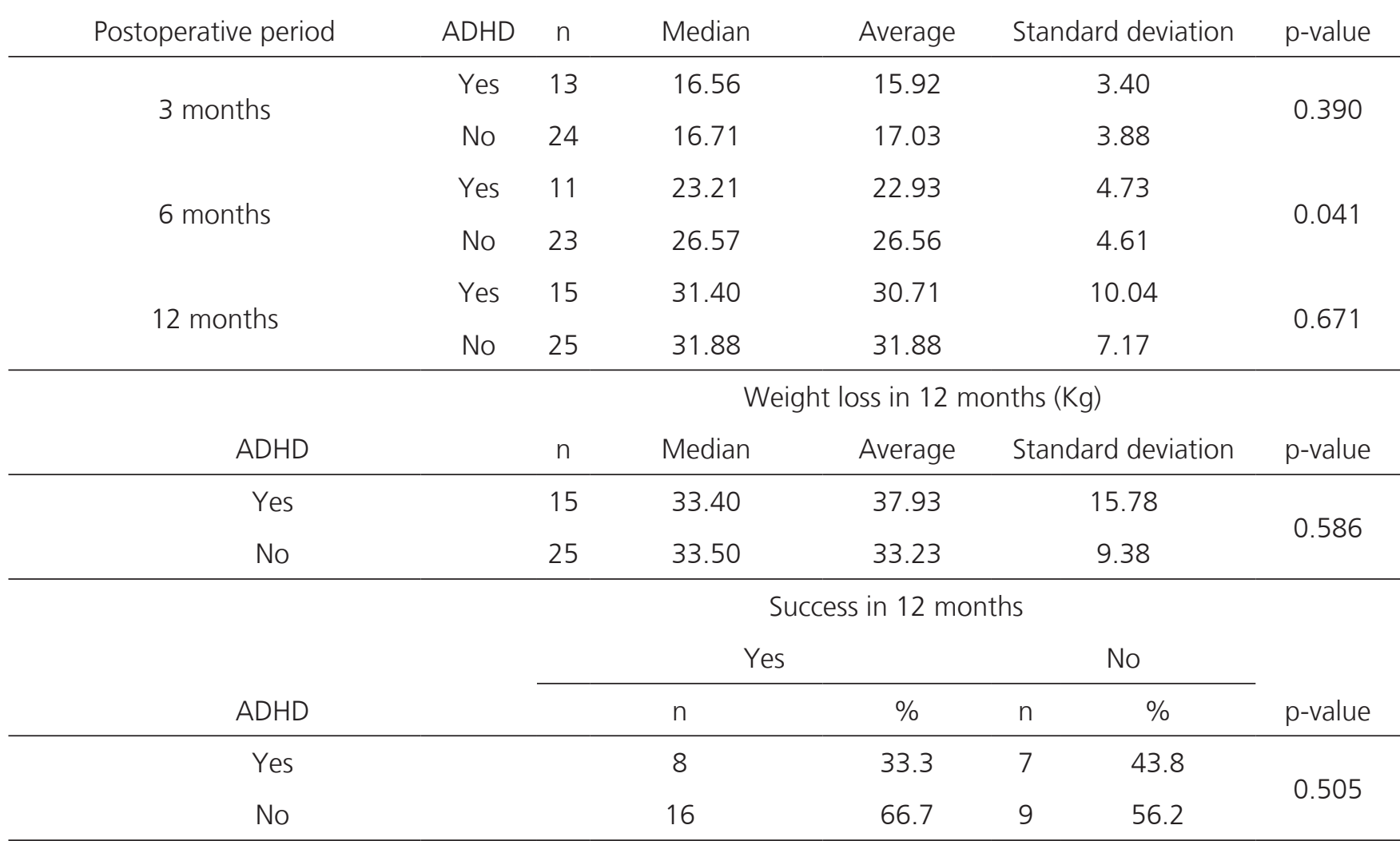

Success= loss greater than $50 \%$ of excess weight. T test for means to BMI, Mann-Whitney test for weight and Chi-square test for success.

superobese like ours, with $37.5 \%$ diabetics and $15 \%$ superobese, the percentage of excess weight loss is lower than the general average. Several studies analyzed this fact, such as the one from Schauer et al. ${ }^{31}$, who had a sample of 275 patients, $6.5 \%$ of them diabetic, who presented a mean weight loss of $68.8 \%{ }^{31}$. Wittgrove et al. ${ }^{30}$ found $17 \%$ of diabetics and observed $80 \%$ weight loss in 18 months, but considering only the diabetic population the value was approximately $70 \%$.

When assessing ADHD with the evolution of patients after Gastric Bypass, we found no significant differences between the groups, leading to the belief that ADHD did not influence the procedure success. Although we found a single difference in the percentage of BMI loss at six months, this trend did not persist in the 12-month period.

Even with limited sample size, lacking sufficient external validity to prove that ADHD would affect surgery success, the data are relevant because there is a huge shortage of such studies. It is known that individuals with ADHD have a higher mean BMI and even less weight loss with clinical obesity treatment ${ }^{17}$. Concurrently, the higher the BMI, the greater the surgical morbidity and mortality ${ }^{32}$. Thus, it is expected that the treatment of such patients since the preoperative period allows better weight loss before the procedure and provides reduction of surgical complications.

We conclude from our study that patients with ADHD have a higher BMI on average. However, bariatric surgery success of was not affected by the disease. This study has limitations on the sample size of and may not have statistical strength for definitive conclusions. However, these are preliminary results and further prospective studies are needed, with larger samples, longer follow-up times and multivariate analysis of the different confounding factors. 


\begin{abstract}
Objetivos: analisar possíveis efeitos negativos do Transtorno do Déficit de Atenção e Hiperatividade (TDAH) no sucesso da cirurgia bariátrica. Métodos: foram avaliados 40 pacientes submetidos à cirurgia bariátrica e com acompanhamento pós-operatório regular mínimo de um ano. Todos foram submetidos ao questionário preconizado na quarta edição do Diagnostic and Statistical Manual (DSM-IV) da Associação Americana de Psiquiatria para TDAH e analisados os dados pós operatórios. Resultados: quinze (38\%) pacientes apresentaram questionário positivo para TDAH. Os pacientes com TDAH apresentaram IMC maior do que os pacientes sem o transtorno $\left(45,8 \times 40,9 \mathrm{Kg} / \mathrm{m}^{2} ; \mathrm{p}=0,017\right)$, mantendo-se a diferença em todas as etapas do pós-operatório. Não foi encontrada diferença estatisticamente significativa no sucesso da cirurgia (33,3\% x 66,7\%; $p=0,505)$, e na redução do IMC $(30,71 \% \times 31,88 \% ; p=0,671)$ após um ano do procedimento. Conclusão: pacientes com TDAH apresentam maior IMC, entretanto, a presença do TDAH não apresenta influência no sucesso da cirurgia bariátrica e na redução do IMC.
\end{abstract}

Descritores: Cirurgia Bariátrica. Obesidade. Transtorno do Déficit de Atenção com Hiperatividade.

\section{REFERENCES}

1. Deitel M. Overweight and obesity worldwide now estimated to involve 1.7 billion people. Obes Surg. 2003;13(3):329-30.

2. WHO. World health statistics 2011. Geneva: World Health Organization; 2011.

3. Brasil. Ministério da Saúde. Secretaria de Vigilância em Saúde. Departamento de Vigilância de Doenças e Agravos não Transmissíveis e Promoção de Saúde. Vigitel Brasil 2012: vigilância de fatores de risco e proteção para doenças crônicas por inquérito telefônico. Brasília: Ministério da Saúde; 2013.

4. Buchwald $\mathrm{H}$. The future of bariatric surgery. Obes Surg. 2005;15(5):598-605.

5. Bhaskaran K, Douglas I, Forbes H, dos-Santos-Silva I, Leon DA, Smeeth L. Body-mass index and risk of 22 specific cancers: a population-based cohort study of 5-24 million UK adults. Lancet. 2014;384(9945):755-65.

6. Clinical guidelines on the identification, evaluation, and treatment of overweight and obesity in adults--the evidence report. National Institutes of Health. Obes Res. 1998;6 Suppl 2:51S-209S. Erratum: Obes Res. 1998;6(6):464.

7. Sjöström L, Lindroos AK, Peltonen $M$, Torgerson J, Bouchard C, Carlsson B, et al. Lifestyle, diabetes, and cardiovascular risk factors 10 years after bariatric surgery. N Engl J Med. 2004;351(26):2683-93.

8. Fobi MA. Surgical treatment of obesity: a review. J Natl Med Assoc. 2004;96(1):61-75.

9. Karmali S, Brar B, Shi X, Sharma AM, de Gara C, Birch DW. Weight recidivism post-baria- tric surgery: a systematic review. Obes Surg. 2013;23(11):1922-33.

10. Sjöström CD, Lissner L, Wedel H, Sjöström L. Reduction in incidence of diabetes, hypertension and lipid disturbances after intentional weight loss induced by bariatric surgery: the SOS Intervention Study. Obes Res. 1999;7(5):477-84.

11. Matthews M, Nigg JT, Fair DA. Attention deficit hyperactivity disorder. Curr Top Behav Neurosci. 2014;16:235-66.

12. Faraone SV, Perlis RH, Doyle AE, Smoller JW, Goralnick JJ, Holmgren MA, et al. Molecular genetics of attention-deficit/hyperactivity disorder. Biol Psychiatry. 2005;57(11):1313-23.

13. Polanczyk GV, Casella EB, Miguel EC, Reed UC. Attention deficit disorder/hyperactivity: a scientific overview. Clinics (Sao Paulo). 2012;67(10):1125-6.

14. Willcutt EG. The prevalence of DSM-IV attention-deficit/hyperactivity disorder: a meta-analytic review. Neurotherapeutics. 2012;9(3):490-9.

15. Mattos $P$, Palmini A, Salgado CA, Segenreich D, Grevet $E$, de Oliveira IR, et al. Brazilian consensus of specialists on the diagnosis of attention-deficit/ hyperactivity disorder in adults. Rev Psiquiatr Rio GdSul. 2006;28(1):50-60.

16. Johnson RJ, Gold MS, Johnson DR, Ishimoto T, Lanaspa MA, Zahniser NR, et al. Attention-deficit/hyperactivity disorder: is it time to reappraise the role of sugar consumption? Postgrad Med. 2011;123(5):39-49.

17. Levy LD, Fleming JP, Klar D. Treatment of refractory obesity in severely obese adults following 
management of newly diagnosed attention deficit hyperactivity disorder. Int J Obes (Lond). 2009;33(3):326-34.

18. Geloneze B, Pareja JC. Cirurgia bariátrica cura a síndrome metabólica? Arq Bras Endocrinol Metab. 2006;50(2):400-7.

19. American Psychiatric Association. Diagnostic and statistical manual of mental disorders DSM-IV. 4th ed. Washington, DC: American Psychiatric Association; 1994.

20. van Hout GC, Verschure SK, van Heck GL. Psychosocial predictors of success following bariatric surgery. Obes Surg.2005;15(4):552-60.

21. Herpertz S, Kielmann R, Wolf AM, Hebebrand J, Senf W. Do psychosocial variables predict weight loss or mental health after obesity surgery? A systematic review. Obes Res. 2004;12(10):1554-69.

22. Altfas JR. Prevalence of attention deficit/hyperactivity disorder among adults in obesity treatment. BMC Psychiatry. 2002;2:9.

23. Pagoto SL, Curtin C, Bandini LG, Anderson SE, Schneider KL, Bodenlos JS, et al. Weight loss following a clinic-based weight loss program among adults with attention deficit/hyperactivity disorder symptoms. Eat Weight Disord. 2010;15(3):e166-72.

24. Gruss B, Mueller A, Horbach T, Martin A, de Zwaan M. Attention-deficit/hyperactivity disorder in a prebariatric surgery sample. Eur Eat Disord Rev. 2012;20(1):103-7.

25. Alfonsson S, Parling T, Ghaderi A. Screening of adult ADHD among patients presenting for bariatric surgery. Obes Surg. 2012;22(6):918-26.

26. Cortese S, Faraone SV, Bernardi S, Wang S, Blanco $C$. Adult attention-deficit hyperactivity disorder and obesity: epidemiological study. Br J Psychiatry. 2013;203(1):24-34

27. Sjöström L, Narbro K, Sjöström CD, Karason K, Larsson B, Wedel $H$, et al. Effects of bariatric surgery on mortalityin Swedish obese subjects. N Engl J Med. 2007;357(8):741-52.

28. Costello EJ, Keeler GP, Angold A. Poverty, race/ ethnicity, and psychiatricdisorder: a study of rural children. Am J Public Health. 2001;91(9):1494-8.

29. Brethauer SA, Chand B, Schauer PR. Risks and benefits of bariatric surgery: current evidence. Cleve Clin J Med. 2006;73(11):993-1007.

30. Wittgrove AC, Clark GW. Laparoscopic gastric bypass, Roux-en-Y- 500 patients: technique and results, with 3-60 month follow-up. Obes Surg. 2000; 10(3):233-9.

31. Schauer PR, Ikramuddin S, Gourash W, Ramanathan R, Luketich J. Outcomes after laparoscopic Roux-en-Y gastric bypass for morbid obesity. Ann Surg. 2000;232(4):515-29.

32. Bruschi Kelles SM, Diniz MF, Machado CJ, Barreto SM. Mortality rate after open Roux-in-Y gastric bypass: a 10-year follow-up. Braz J Med Biol Res. 2014;47(7):617-25.

Received in: 17/10/2016

Accepted for publication: 01/12/2016

Conflict of interest: none.

Source of funding: none.

\section{Mailing address:}

Doglas Gobbi Marchesi

E-mail: doglas.marchesi@gmail.com doglas.marchesi@ebserh.gov.br 